Hlotova Y., Cats O. and Meijer S. (2014). Measuring Bus Driver's Occupational Stress under Changing Working Conditions. Transportation Research Record, 2415, 13-20. DOI: 10.3141/2415-02. Available at: http://trb.metapress.com/content/2707648k87262mh0/?genre=article\&id=doi\%3a10.3141\%2f2415-02

\title{
Measuring Bus Driver's Occupational Stress under Changing Working Conditions
}

Yevheniia Hlotova

Department of Transport Science, Royal Institute of Technology (KTH)

Teknikringen 10, 11428 Stockholm, Sweden

Phone number: +4687908816

Fax number: +468212899

hltova@kth.se

Oded Cats (corresponding author)

Department of Transport Science, Royal Institute of Technology (KTH)

AND

Department of Transport and Planning, Delft University of Technology P.O. Box 5048, 2600 GA Delft, The Netherlands

Phone number: +31152781384

Fax number: +31152787956

o.cats@tudelft.nl

Sebastiaan Meijer

Department of Transport Science, Royal Institute of Technology (KTH) AND

Faculty of Technology, Policy and Management, Delft University of Technology, The Netherlands

Teknikringen 72, 11428 Stockholm, Sweden

Phone number: +4687908071

Fax number: +468212899

smeijer@kth.se

Keywords: stress, heart rate, bus driver control strategy, weather, crew management 
Hlotova Y., Cats O. and Meijer S. (2014). Measuring Bus Driver's Occupational Stress under Changing Working Conditions. Transportation Research Record, 2415, 13-20. DOI: 10.3141/2415-02. Available at: http://trb.metapress.com/content/2707648k87262mh0/?genre=article\&id=doi\%3a10.3141\%2f2415-02

2 Stress is an immense problem in modern society, as about half of the occupational 3 illnesses are directly or indirectly related to it. The work of a bus driver is typically 4 associated with high stress levels which negatively influence individual well-being as 5 well as workforce management. The current study examines the impact of newly6 proposed working conditions on bus drivers' occupational stress by monitoring heart 7 rate and a mental workload questionnaire in operational driving conditions. The main 8 determinants of stress levels were identified through multiple regression analysis. The 9 results indicate that bus drivers experienced considerably lower stress levels under a 10 new control strategy that shifts the performance objective from schedule adherence to service regularity. Higher stress levels were recorded during extreme weather conditions, peak hours and among inexperienced drivers. The measurements were performed with low-cost sports devices that can easily be used by practitioners. 
Hlotova Y., Cats O. and Meijer S. (2014). Measuring Bus Driver's Occupational Stress under Changing Working Conditions. Transportation Research Record, 2415, 13-20. DOI: 10.3141/2415-02. Available at: http://trb.metapress.com/content/2707648k87262mh0/?genre=article\&id=doi\%3a10.3141\%2f2415-02

\section{INTRODUCTION}

As a passenger who takes a bus every day it is difficult to imagine that driving a bus is considered as one of the more stressful occupations. Bus drivers (also known as bus operators in the US) have to perform several tasks simultaneously including driving safely, adhering to timetables and customer service duties. In particular, the necessity to comply with timetables under increasingly congested roads contributes the most to the strain and pressure associated with bus drivers' workload (1). This in turn increases the risk of health and mental problems. In a comprehensive review of 50year research of bus driver's well-being, Tse et al. (1) synthesize its predisposition to poor health. Moreover, growing traffic, aggresive passengers and increasingly tight running schedules due to market competition are continuously growing threats to drivers' well-being. The study signified the necessity "for bus operators to improve workplace practices to reduce job stressors and ameliorate the work environment of bus drivers".

Bus drivers' working conditions were studied extensively by researchers as well as the public transport industry, because of the job's impopularity on the market, high labor turnover and early retirement caused by health problems. Kompier (2) reported that more than $50 \%$ of the drivers considered their job very demanding, stressful and rushed, 55\% and 53\% of respondents named peak running times and public enquiring, respectively, as the main stressors. Furthermore, 25\% of bus drivers reported that schedules were so tight that safety was compromised on a daily basis. Consequently, driving a bus is considered as an occupation with dangers for health and overall well-being; bus drivers have higher levels of absenteeism and disabilities compared to other occupational groups. They more often experience psychological problems: strong feeling of fatigue, tension and mental overload, sleeping problems in addition to muscular-skeletal disorders (2). Numerous studies have shown that bus drivers worldwide suffer from various heart problems $(1,3,4,5,6)$. Furthermore, comparative studies found that bus drivers are in higher risk for coronary heart diseases than other skilled workers (e.g. 5).

The existing body of literature on key determinants of occupational stress shows that the workplace is a substantial source of both demands and pressures causing stress, as well as a structural and social resource to counteract stress. Mental stress is an immense problem in modern society: about half of occupational illnesses are directly or indirectly related to stress. Work-related stress is believed to be the main reason of increasing number of mental disorders (7). There are different sources of stress at work, those related to job itself, organization and the role of the worker in it, career development, relationship at work, organizational structure and climate. Intrinsic sources of stress are long hours, work overload, time pressure, difficult or complex tasks, lack of breaks, lack of variety and poor physical work conditions (space, temperature, light) (8). Kompier (9) described the following reasons for stress at work among urban drivers: not sufficient time to complete the job to one's satisfaction; deficiency of clear job description, absence of acknowledgment or reward for good job accomplishment, inability or absence of opportunity to express complaints, lots of responsibilities but little power or decision-making capacity, uncooperative superiors, co-workers, or subordinates, etc. Karasek (10) presented a stress-management model of job strain, which explains occupational stress as function of working conditions. Occupations characterized by high demands and low control, especially when it is difficult to meet the work requirements along with low social support, contribute the most to the job stress. 
Hlotova Y., Cats O. and Meijer S. (2014). Measuring Bus Driver's Occupational Stress under Changing Working Conditions. Transportation Research Record, 2415, 13-20. DOI: 10.3141/2415-02. Available at: http://rb.metapress.com/content/2707648k87262mh0/?genre=article\&id=doi\%3a10.3141\%2f2415-02

A number of studies defined and examined a variety of stressors particularly with the increase of stress hormones during driving. Moreover, surveys indicate that among the main difficulties working as an urban bus driver is the threat of physical violence, traffic congestion, risk of having big sums of money, lack of knowledge about how the company is managed, no opportunities to recommend work changes, peak running times $(9,12)$. A survey with a large sample of urban bus drivers in Sweden highlighted that drivers often reported a conflict between their desire to provide professional level of service and relentless time pressure to keep the schedule (13).

Previous studies have established the key stressors related to transit occupation and their consequences on each driver and organization as a whole. However, there is lack of research on measures to improve bus drivers' occupational stress and their potential implications. Tse et al. (1) concluded from their review that "longitudinal studies are needed with appropriate control groups, to test the impact of reducing physical and psychological stressors on the driving workforce rather than additional investigations to describe stressors". They also strongly recommended that bus operators would work together with researchers, trade unions, policy makers and bus drivers themselves in order to reduce bus drivers' stress and strain during duty.

The purpose of this study is to evaluate the impact of newly-proposed working conditions on bus drivers' stress levels. In particular, we analyze the impact of a new control strategy, which is more adaptive to changing traffic conditions. The strategy aims to continuously maintain even headways between consecutive buses by speed and dwell time adjustments (14). The strategy is implemented through a real-time display called BusPC located at the driver cabin which indicates the difference between the headway from the preceeding bus and the headway from the succeeding bus.

The even-headway control strategy was recently tested on trunk lines in Stockholm, Sweden (15) and resulted with improved service regularity. Prior to its implementation, driver union representatives raised the concern that the need to constantly monitor bus progress based on fellow buses will introduce a new source of stress for bus drivers. However, drivers in practice had to take few and minor corrections once they became accustomed to the new strategy and bus drivers representatives reported lower level of stress by the end of the experiment. This effect was not measured and hence could not be quantified or verified. The current study was initiated in order to measure whether there is indeed such an effect. The current study utilizes a follow-up field experiment that took place in Stockholm during the fall and winter of 2013. We monitored mental workload of bus drivers during driving in the real-time changing working conditions by measuring heart rate and inquiring perceived stress levels.

This paper is organized as follows: the next section describes the methods that were applied in the experiment design as well as the data collection procedure. Section 3 presents the analysis and results including sample characteristics and descriptive statistics. In addition, multiple linear regression models of drivers' heart rate variability were estimated in order to identify the main explanatory variables. Section 4 discusses the results and their implications. Section 5 concludes the paper and provides directions for future work. 
Hlotova Y., Cats O. and Meijer S. (2014). Measuring Bus Driver's Occupational Stress under Changing Working Conditions. Transportation Research Record, 2415, 13-20. DOI: 10.3141/2415-02. Available at: http://trb.metapress.com/content/2707648k87262mh0/?genre=article\&id=doi\%3a10.3141\%2f2415-02

\section{EXPERIMENT DESIGN}

The experimental methods used for this study combine measured and reported data. In order to adequately analyze the sources and impacts of stress, heart rate variability (HRV, which is the inverse of heart rate - HR) is often used as a measure mental stress. This indicator measures the heart's ability to react to regulatory stimulus, which influences its rhythm. Measured data consisted of HR, speed and position (GPS) data on the route. The indicator of stress was HRV. HR was measured by a portable heart monitor. Drivers had worn a heart rate belt during one block of 2-2.5 hours (block is on-duty time interval allocated between two breaks). HRV was derived from HR, using the following relationship (16) :

$$
H R V=\left(\frac{60}{H R}\right)
$$

HRV is also known in the literature as RR interval and is expressed in msec.

The HRV data derived from HR is considered reliable and in most cases as exact as data derived from Electrocardiography, with the exception of patients that have any kind of cardiology dysfunction (16). None of the drivers in our sample acknowledged having any heart related diseases. The validity of portable heart monitors was verified in previous studies $(17,18,19,20)$ which concluded that it is considered a reliable tool for HR data measurements. However, most of these studies used expensive and complex devices for doing so, something that the current study aimed to overcome.

Reported data was collected via self-reported questionnaires, which the drivers filled in. The questionnaires were designed to include factors other than stress and cognitive load, which could influence physiological processes and variation of heart rate. Drivers filled in two sets of questions - prior to the block and immediately after its completion. The first questionnaire consisted of individual-specific attributes (gender, age, experience, time into the shift, medicine consumption, heart problems) and habits (e.g. smoking, coffee consumption). In addition, respondents were inquired about their emotional state by indicating their position on a one to five scale with respect to pair of polar emotions (e.g. happiness/unhappiness, stressfulness/peacefulness). The second questionnaire following the block completion included questions concerning the subjective perception of the performed ride by reporting experienced time pressure, driving style and stressors on a one to five scale.

The study investigated bus drivers' occupational stress in changing working conditions in Stockholm. Table 1 summarizes the conditions - weather, control strategy, driver scheduling - that were associated with each of the experiment days. It is evident that drivers exercised distinguished working conditions on each of the days included in the experiment. The initial aim was to measure stress under even-headway holding strategy in contrast to schedule-based. It was planned to register HR during the last week of even-headway holding strategy trial. However, this plan was not realized due to a snow storm, which took place on the second day of measurements, upon which the schedule-based strategy had to be restored. The extreme weather conditions resulted with exceptional working conditions as traffic and service were severely disrupted. Similar working conditions could be caused by other disturbances such as technical failure, strike or traffic accident.

The measurements of control group took place in March, when weather conditions were much more favorable and only schedule-based holding strategy was in place. In addition, during December period drivers worked under so-called "no interlining", which implied that they drove back and forth on a single line throughout their shift 
Hlotova Y., Cats O. and Meijer S. (2014). Measuring Bus Driver's Occupational Stress under Changing Working Conditions. Transportation Research Record, 2415, 13-20. DOI: 10.3141/2415-02. Available at: http://rb.metapress.com/content/2707648k87262mh0/?genre=article\&id=doi\%3a10.3141\%2f2415-02

while in March the drivers could drive several different lines during the same day.

Table 1 Experimental Design

\begin{tabular}{|c|c|c|c|}
\hline Day & $\begin{array}{l}\text { Weather and } \\
\text { traffic }\end{array}$ & Control strategy & $\begin{array}{c}\text { Driver } \\
\text { scheduling }\end{array}$ \\
\hline $\begin{array}{l}4.12 .2012 \\
\text { Tuesday }\end{array}$ & Normal & Even-headway & No interlining \\
\hline $\begin{array}{c}5.12 .2012 \\
\text { Wednesday }\end{array}$ & $\begin{array}{c}\text { Snowstorm }(40 \mathrm{~cm}), \\
\text { traffic was almost } \\
\text { put to halt, only } \\
\text { trunk lines run }\end{array}$ & $\begin{array}{l}\text { Control-center } \\
\text { steer operations }\end{array}$ & No interlining \\
\hline $\begin{array}{l}6.12 .2012 \\
\text { Thursday }\end{array}$ & Snow ramped up & Schedule-based & No interlining \\
\hline $\begin{array}{c}7.12 .2012 \\
\text { Friday }\end{array}$ & $\begin{array}{c}\text { Snowy roads, Busy } \\
\text { before Holidays } \\
\text { period }\end{array}$ & Schedule-based & No interlining \\
\hline $\begin{array}{l}25.3 .2013 \\
\text { Monday }\end{array}$ & Normal & Schedule-based & Interlining \\
\hline $\begin{array}{c}26.3 .2013 \\
\text { Tuesday }\end{array}$ & Normal & Schedule-based & Interlining \\
\hline
\end{tabular}

Data was collected on trunk line 3 only in order to remove potential intervening factors. Line 3 connects two major hospital campuses through a $9.5 \mathrm{~km}$ long route which provides a north-south connection through Stockholm inner-city (Figure 1). The line serves 25 stops of which 3 stops along the line are used as timetable regulation stops in case the bus runs early compared with the timetable. The commercial speed is approximately $10 \mathrm{~km} /$ hour and the planned headway is $6-8$ minutes. Line 3 is operated by articulated buses and serves 30,000 passengers per day per direction.

Two research assistants were positioned in a major driver relief point in the city center. Drivers were recruited on-site on a voluntarily basis, when the study purpose was explained to them. Participants wore a heart rate belt and carried a mobile GPS device (Garmin 800 series) during a single driving block along with answering two series of questions before and after driving. No incentive was offered other than receiving a personal record containing the recorded data. 69 people were asked to participate and in total, 38 people took part in the experiment. In general, drivers were willing to participate and share their experience if they knew that the main goal of the study was to evaluate different working conditions and stress level.

The portable heart monitor consists of computer touch screen and HR monitor, which wirelessly connects with each other. Drivers had to wear the HR monitor and take the touch screen with them en-route. The assistants had to ensure stable connection between two devices as well as established satellite connection. All measurements were taken between 6:30 and 20:00. Data was considered unreliable in one of the following cases: the GPS signal was lost and therefore no speed was registered, HR data was not registered or HR data was constant and didn't change for 30 seconds. Finally, complete heart rate data was recorded successfully for 30 drivers. In total, more than 70 hours of adequate data was measured, with a second-level frequency. This yielded more than 140,000 raw observations. Figure 1(b) illustrates the resolution of speed and heart rate recorded during a single block. 
Hlotova Y., Cats O. and Meijer S. (2014). Measuring Bus Driver's Occupational Stress under Changing Working Conditions. Transportation Research Record, 2415, 13-20. DOI: 10.3141/2415-02. Available at: http://trb.metapress.com/content/2707648k87262mh0/?genre=article\&id=doi\%3a10.3141\%2f2415-02

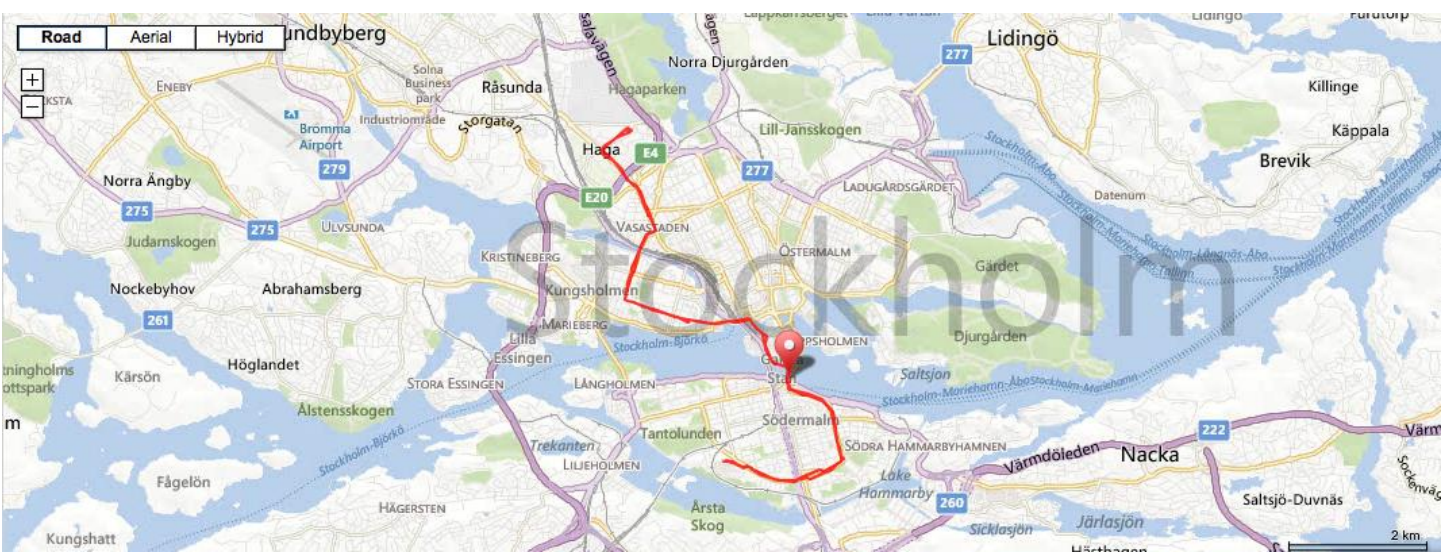

(a)

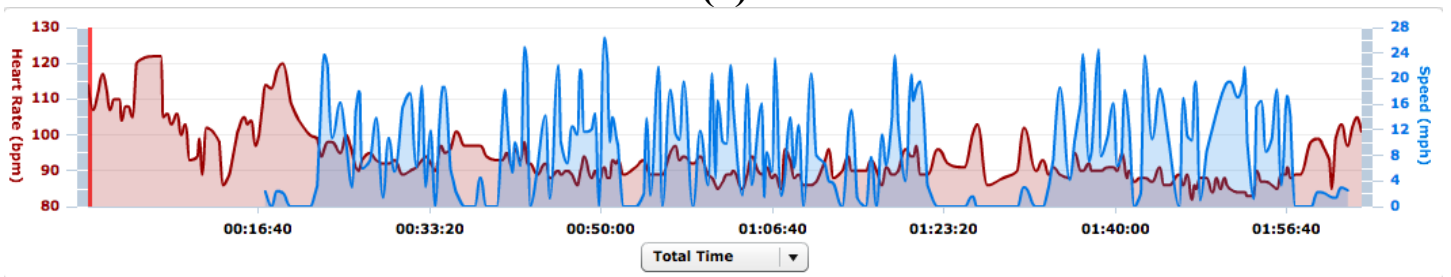

Figure 1 Line 3 route (a); a snapshot of heart rate and speed data (b)

\section{ANALYSIS AND RESULTS}

\subsection{Exploratory Data Analysis}

Most of the drivers, who participated in the study, were between 40 and 60 years old, among which 6 women and 24 men. It generally represents the most common age and gender distribution of bus drivers on line 3. Most of the drivers had long driving experience - more than 5 years, 9 people had more than 20 years of experience, while 6 drivers had less than 6 years of experience.

Concerning habits and physical state, including smoking, coffee, heart problems and medicine, the results from the questionnaire communicated that none of the drivers reported any heart problems, 4 drivers reported to take medicine, which influence heart activity, 8 drivers acknowledged to smoke and 22 drivers reported to take coffee every day.

None of the drivers reported to be seriously distracted by BusPC display, five people reported to be slightly distracted during the December period with three drivers on Monday, when the even-headway system was on and two more on Friday and none of the drivers reported to be distracted by BusPC in March. Additionally, only one driver reported to feel slight discomfort during driving due to the equipment and one person acknowledged feeling psychologically more stressed due to the fact that her heart rate was measured in order to register stress.

Table 2 shows the average heart rate for people who don't have any heart, blood etc. problems, people who do not do much sport and have "regular" jobs together with average sample HR for female and male accordingly. Physiologically, heart rate varies between female and male and it also slightly changes depending on the age category. Most of the drivers of all age categories for both genders have 
Hlotova Y., Cats O. and Meijer S. (2014). Measuring Bus Driver's Occupational Stress under Changing Working Conditions. Transportation Research Record, 2415, 13-20. DOI: 10.3141/2415-02. Available at: $\mathrm{http} / /$ trb.metapress.com/content/2707648k87262mh0/?genre=article\&id=doi\%3a10.3141\%2f2415-02

average HR much higher than the person's average heart rate in the relaxed state. Only women drivers of age 56-65 years old and men drivers of age 63-70 years old had average HR around the standard HR of relaxed state. There were no women in the study of age between 18 to 45 years old and neither those who older than 65 . For the analysis only HR data during driving was included.

Table 2 Average Heart Rate of a Healthy Person and Sample Average

\begin{tabular}{|lcccccc|} 
Age & $\mathbf{1 8 - 2 5}$ & $\mathbf{2 6 - 3 5}$ & $\mathbf{3 6 - 4 5}$ & $\mathbf{4 6 - 5 5}$ & $\mathbf{5 6 - 6 5}$ & $\mathbf{6 5 +}$ \\
\hline Female* & $67-76$ & $66-74$ & $66-76$ & $67-75$ & $66-75$ & $66-74$ \\
\hline Sample female & - & - & - & 87 & 69 & - \\
\hline Male* & $63-71$ & $63-72$ & $65-73$ & $65-74$ & $63-73$ & $63-71$ \\
\hline Sample male & 92 & 85 & 79 & 80 & 78 & 70 \\
\hline
\end{tabular}

(*) Source: The sport and science resource,

http://www.topendsports.com/testing/heart-rate-resting-chart.htm

10

Table 3 presents summary statistics of HR depending on the day of registration. HR data includes only driving time. Snow storm day definitely stands out in comparison to all other days.

Table 3 Summary Statistics, Variables of Interest

\begin{tabular}{|lcccccc|}
\hline \multicolumn{1}{|c}{ Day } & $\begin{array}{c}\text { Number of } \\
\text { participants }\end{array}$ & $\begin{array}{c}\text { Number } \\
\text { of records }\end{array}$ & Mean & $\begin{array}{c}\text { Std. } \\
\text { Dev. }\end{array}$ & Min & Max \\
\hline Total sample & 30 & 141,163 & 81.0 & 11.3 & 55 & 138 \\
\hline December & 19 & 93,464 & 81.6 & 10.4 & 58 & 138 \\
\hline March & 11 & 47,699 & 79.9 & 12.8 & 55 & 124 \\
\hline $\begin{array}{l}\mathbf{4 . 1 2 . 2 0 1 2}, \\
\text { Even-Headway }\end{array}$ & 6 & 21,296 & 78.9 & 7.7 & 58 & 118 \\
\hline $\begin{array}{l}\mathbf{5 . 1 2 . 2 0 1 2 ,} \\
\text { Snow Storm }\end{array}$ & 3 & 21,191 & 90.9 & 8.8 & 64 & 138 \\
\hline $\begin{array}{l}\text { 6.12.2012 } \\
\text { December }\end{array}$ & 5 & 26,145 & 77.2 & 10.8 & 59 & 124 \\
\hline $\begin{array}{l}\mathbf{7 . 1 2 . 2 0 1 2}, \\
\text { December }\end{array}$ & 5 & 24,832 & 80.8 & 7.9 & 59 & 116 \\
\hline
\end{tabular}

\subsection{Model Estimation}

Analysis of variances (ANOVA) was performed using with the Least-Squares (OLS) models procedure available in Stata Data analysis and statistical software package. The differences between various working conditions were tested.

Table 4 provides summary statistics of all the variables of interest, included in the model. Spatial related variables were computed: regulation stops and accumulated time driven within one block. Regulation stops' variable reflects the distance from the next regulation stop, in minutes. In addition, potential covariates (age, gender, experience, smoking, everyday coffee, coffee before the ride; how long the driver worked within the shift before participating in the experiment, mood before the ride, calmness, fatigue, reported time pressure and driving style after the ride) were added to the regression model. 
Hlotova Y., Cats O. and Meijer S. (2014). Measuring Bus Driver's Occupational Stress under Changing Working Conditions. Transportation Research Record, 2415, 13-20. DOI: 10.3141/2415-02. Available at: $\mathrm{http}: / /$ trb.metapress.com/content/2707648k87262mh0/?genre=article\&id=doi\%3a10.3141\%2f2415-02

Table 4 Summary Statistics

\begin{tabular}{|lcc|}
\hline Variable & Mean & Std.dev \\
\hline HRV & 754.39 & 102.08 \\
\hline Day with even-headway holding strategy, binary & 0.15 & 0.36 \\
\hline Day with snowstorm, binary & 0.15 & 0.36 \\
\hline Day after the snowstorm, binary & 0.18 & 0.39 \\
\hline Friday before Christmas, binary & 0.18 & 0.38 \\
\hline Regulation stops, minutes & 541.51 & 502.35 \\
\hline Accumulated time driven, minutes & 3899.42 & 2584.62 \\
\hline Peak Hour, binary & 0.24 & 0.43 \\
\hline Age 24-67 years old, continuous & 50.26 & 8.41 \\
\hline Gender, binary & 0.19 & 0.39 \\
\hline Experience 0-2 years, binary & 0.08 & 0.28 \\
\hline Experience 2-5 years, binary & 0.16 & 0.37 \\
\hline Experience 6-10 years, binary & 0.20 & 0.40 \\
\hline Experience 11-20 years, binary & 0.20 & 0.40 \\
\hline Experience more than 21 years, binary & 0.37 & 0.48 \\
\hline Time within the shift: 0-1 hours, binary & 0.16 & 0.37 \\
\hline Time within the shift: 1-3 hours, binary & 0.44 & 0.5 \\
\hline Time within the shift: 3-6 hours, binary & 0.30 & 0.46 \\
\hline Time within the shift: 6-8 hours, binary & 0.91 & 0.29 \\
\hline Medicine influencing heart activity, binary & 0.41 & 0.2 \\
\hline Smoking, binary & 0.28 & 0.45 \\
\hline Everyday coffee, binary & 0.78 & 0.41 \\
\hline Personal feelings of happiness/unhappiness & -0.90 & 0.87 \\
\hline Personal perception of stressfulness/peacefulness & -1.52 & 0.59 \\
\hline Personal perception of tiredness & -0.48 & 1.08 \\
\hline Personal perception of driving style & 2.45 & 0.98 \\
\hline Reported time pressure & 3.04 & 0.98 \\
\hline
\end{tabular}

Alternative multiple linear regression model were estimated with HRV as the dependent variable. Note that HRV is the reverse of HR and therefore when HR increases HRV decreases. Hence, cognitive load and stress is associated with decreased HRV. The estimation results of three model specifications are presented in Table 5.

Experience variables were highly correlated with duration in the shift variables. Both experience and duration in the shift were considered to be important and highly correlated with dependent variable, therefore two alternative models were specified and estimated - experience and shift model.

\section{(1) Experience model:}

HRV $=\beta 0+\beta 1 *$ even-headway holding strategy $+\beta 2 *$ snowstorm $+\beta 3 *$ day after snowstorm $+\beta 4 *$ Friday before Christmas $+\beta 5^{*}$ age $+\beta 6 *$ female $+\beta 7^{*}$ experience: 0 2 years $+\beta 8^{*}$ experience: $2-5$ years $+\beta 9^{*}$ experience: $6-10$ years $+\beta 10 *$ experience: more than 21 years $+\beta 11 *$ medicine influencing heart activity $+\beta 12 *$ smoking + $\beta 13 *$ coffee every day $+\beta 14 *$ personal feelings of happiness/unhappiness $+\beta 15^{*}$ personal perception of stressfulness/peacefulness $+\beta 16^{*}$ personal perception of 
Hlotova Y., Cats O. and Meijer S. (2014). Measuring Bus Driver's Occupational Stress under Changing Working Conditions. Transportation Research Record, 2415, 13-20. DOI: 10.3141/2415-02. Available at: http://trb.metapress.com/content/2707648k87262mh0/?genre=article\&id=doi\%3a10.3141\%2f2415-02

1 tiredness $+\beta 17 *$ reported time pressure $+\beta 18^{*}$ personal perception of driving style

(2) Shift model:

HRV $=\beta 0+\beta 1 *$ even-headway holding strategy $+\beta 2 *$ snowstorm $+\beta 3 *$ day after snowstorm $+\beta 4^{*}$ Friday before Christmas $+\beta 5^{*}$ age $+\beta 6^{*}$ female $+\beta 7^{*}$ medicine influencing heart activity $+\beta 8 *$ smoking $+\beta 9 *$ coffee every day $+\beta 10 *$ personal feelings of happiness/unhappiness $+\beta 11^{*}$ personal perception of stressfulness/peacefulness $+\beta 12^{*}$ personal perception of tiredness $+\beta 13^{*}$ reported time pressure $+\beta 14^{*}$ regulation stops $+\beta 15^{*}$ accumulated time driven $+\beta 16^{*}$ peakhour $+\beta 17^{*}$ elapsed shift duration: $0-1$ hours $+\beta 18^{*}$ elapsed shift duration: $3-6$ hours $+\beta 19^{*}$ elapsed shift duration: 6-8 hours $+\varepsilon$.

Where $\varepsilon$ is the error term.

An additional model provides a compact shortlist of the most important explanatory variables. The model was estimated based on the aggregation of heart-rate records at the individual level.

\section{(3) Compact model:}

$\mathrm{HRV}=\beta 0+\beta 1 *$ even-headway holding strategy $+\beta 4 *$ Friday before Christmas + $\beta 5 *$ age $+\beta 7 *$ medicine influencing heart activity $+\beta 8 *$ smoking $+\beta 14 *$ regulation stops $+\beta 15^{*}$ accumulated time driven $+\varepsilon$

In order to improve model robustness, the estimation procedure accounted for the variability of error around the variables (the heteroskedasticity of their error terms). The estimated coefficients are presented in Table 5 along with the corresponding t-stat (in parentheses). All coefficients were statistically significant at the $99 \%$ level with the exception of Friday before Christmas variable for the Compact model which was significant at the $90 \%$ level and the accumulated time driven in the case of Shift model. The dispersion of residuals did not exhibit dependence upon any of the explanatory variables. The Shift and Experience models obtain higher goodness-of-fit measured due to the inclusion of a larger number of explanatory variables while the higher t-stat values are attributed to the larger number of observations used for their estimation. The highest coefficient of determination adjusted R2 is 0.63 , therefore almost $63 \%$ of the variation observed in HRV can be explained by the estimated regression model. 
Hlotova Y., Cats O. and Meijer S. (2014). Measuring Bus Driver's Occupational Stress under Changing Working Conditions. Transportation Research Record, 2415, 13-20. DOI: 10.3141/2415-02. Available at: $\mathrm{http}: / /$ trb.metapress.com/content/2707648k87262mh0/?genre=article\&id=doi\%3a10.3141\%2f2415-02

Table 5 Heart Rate Variability Models

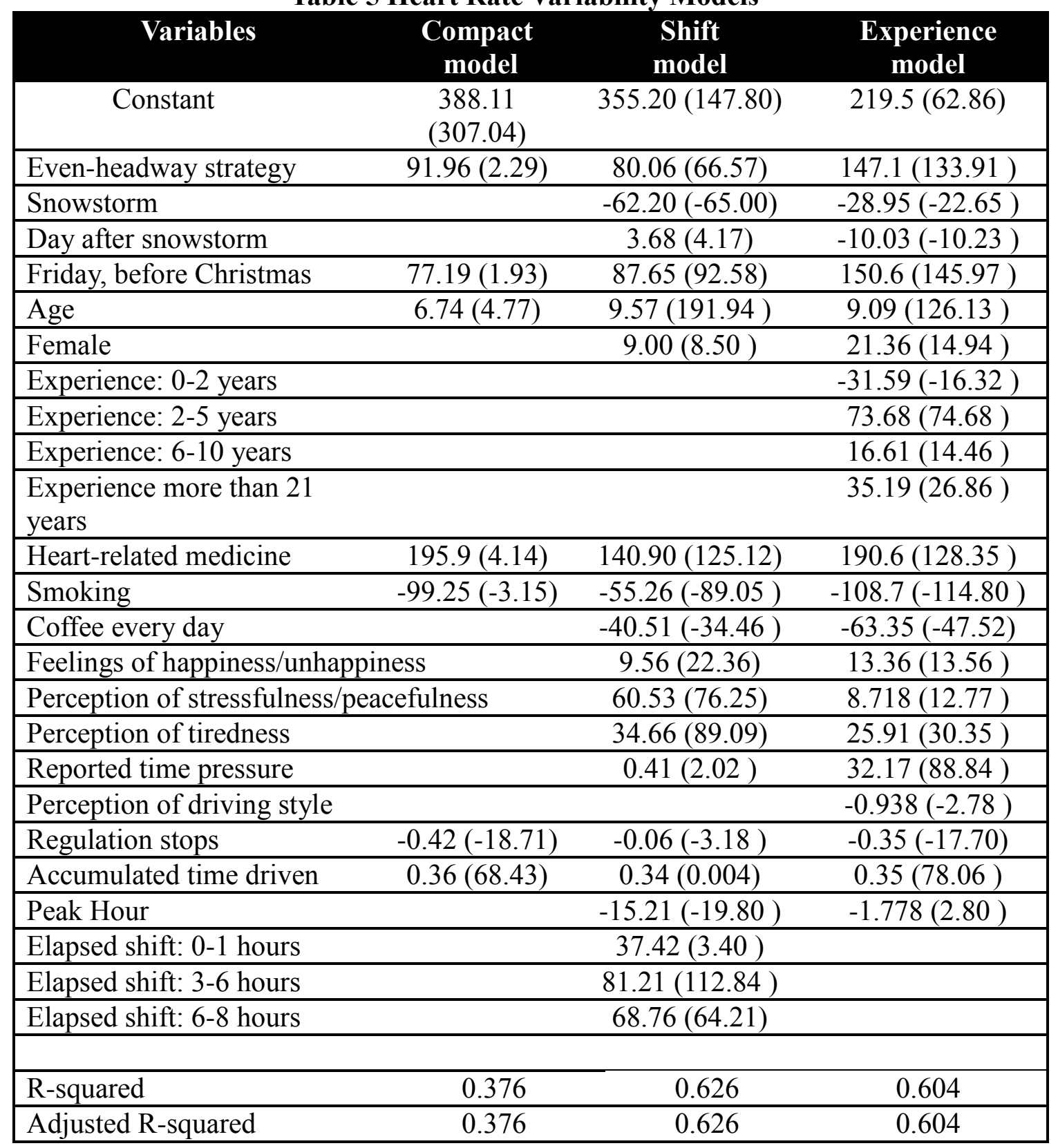

Under even-headway holding strategy, HRV increases significantly. As could be expected, snowstorm conditions caused HRV decrease, especially in the Shift model, which means that the snowstorm caused additional physical and mental load, which resulted in decreased HRV. The day following the snowstorm has an inconclusive pattern with opposite signs on the two estimated models. Therefore, further investigation of the post-snowstorm effect is required in order to determine its impact on drivers. In contrast to our a-priori expectations, Friday before Christmas is associated with a higher HRV as well, in contrast to drivers self-reports.

In relation to individual-specific characteristics, HRV increases with age. This finding is in contradiction to what physiological literature reports (Table 2). It should be noted that age was not correlated with experience, so the reduction is not mediated by experience. Female drivers are likely to have higher HRV compared to men and therefore lower stress level. Comment compared with table. As expected, drivers who 16 have less than 2 years of experience appear to have the lowest HRV pattern. This is 
Hlotova Y., Cats O. and Meijer S. (2014). Measuring Bus Driver's Occupational Stress under Changing Working Conditions. Transportation Research Record, 2415, 13-20. DOI: 10.3141/2415-02. Available at: http://rb.metapress.com/content/2707648k87262mh0/?genre=article\&id=doi\%3a10.3141\%2f2415-02

consistent with other studies which found that drivers with a driving experience of less than 2 years both perceive driving as more stressful than experienced drivers do as well as experience a higher mental strain. Surprisingly, Experience model have shown that people with experience between 11 to 20 years appeared to have lower HRV than people who have worked as bus drivers between 2 and 10 years. This nonmonotonous pattern could perhaps be caused by a three-way interaction between stress, commitment and experience (21).

Shift model has shown that drivers that were 2-3 hours into their shift had the lowest HRV compared to the drivers who worked only less than 1 hour or those who worked more than 3 hours. Additionally, drivers, who were 6-8 hours into their shift appeared to have HRV higher than those who were under 3 hours, but lower than those who were between 3 and 6 hours in their shift.

All model specifications have shown that, people who take medicine, which can influence heart activity; had a lower HRV than people who didn't take any pills affecting the heart. This result is coherent, because most people, who admitted to take medicine, affirmed to take medicine against high blood pressure, which decreases HR. The model also confirms that drivers who smoke on a regular basis have a significantly lower HRV decrease compared to people who do not smoke. Moreover, Experience model confirmed that smoking has even a higher impact on HRV than experience, which means that drivers who don't have significant experience and smoke double their stress level, and those drivers who smoke, but have driving experience of more than 5 years would have decreased HRV approximately similar to inexperienced drivers. The models have also shown that drivers who drink coffee on a regular basis are also associated with lower HRV levels.

The personal perception of driving style was also intimately linked with measured HRV levels. Respondents who reported that their driving style was rather bumpy appeared to have lower HRV compared to those people who acknowledged their drive to be smooth. Naturally, those drivers who after the ride reported to experience time pressure have had lower HRV than those people, who acknowledged not feeling time pressure $(\mathrm{r}=0.25)$.

All model specifications have shown that driving during peak-hour causes HRV decrease. The variable's coefficient is of lower magnitude than expected, presumably due to the fact that timing when the peak-hours occur in Stockholm can vary from day to day (can start or finish earlier or later).

Regulation stops were found to have a statistically significant influence on drivers' stress levels. Indeed, when drivers were approaching stops, where they had to fulfill time alignment, their HRV was decreasing, which gives empirical evidence that proximity to schedule adherence requirements is associated with higher stress levels. The model has shown that the drivers feel more relaxed by the end of their block, in other words the longer the driver is on route HRV is increasing accordingly.

\section{DISCUSSION}

The estimated models suggest that different working conditions influence measured and perceived stress levels. They have also shown that exceptional events, which can negatively affect the driving environment (e.g. snowstorm), are not only reflected in the subjective answers (questionnaire) as perceived stress, but also have a strong explanatory power with regards to HRV. Snowstorm events considerably decreased HRV, while even-headway holding strategy increased it. Furthermore, the high- 
Hlotova Y., Cats O. and Meijer S. (2014). Measuring Bus Driver's Occupational Stress under Changing Working Conditions. Transportation Research Record, 2415, 13-20. DOI: 10.3141/2415-02. Available at: http://trb.metapress.com/content/2707648k87262mh0/?genre=article\&id=doi\%3a10.3141\%2f2415-02

1 resolution data collection enabled the identification of detailed determinant of stress

level which yielded high goodness-of-fit measures.

The results were consistent with previous research in the field of occupational stress and its relation with experience and age. Lack of experience increases stress level, while sufficient experience (11-20 years) is assumed to have an effect of precaution and therefore it has led to higher arousal levels reflected by HRV. Concerning the age, the oldest drivers appeared to be less stressed compared to the younger drivers. This finding is consistent with the study on age differences in stress: coping and appraisal, where the experiment has shown that the oldest people reported to have less problems and those problems they had required less effort to cope with them for the oldest group compared to the other age groups even if problems were of high magnitude (22); it could mean that people with age develop a so-called immunity to stress.

HRV highly correlated with reported personal feelings and stress level as well as with the reported fatigue; in particular drivers who experienced heavy emotions or reported to be stressed had decreased HRV as well as those people who were more tired. Additionally, HRV were highly correlated with self-reported driving style, if drivers reported the ride to be bumpy; they had decreased HRV compared to those who reported the ride to be smooth.

Moreover, the results were consistent with numerous biomedical studies on the influence of coffee and smoking as well as heart affective medicine on HR and HRV. Indeed, coffee every day decreased HRV significantly, which is in line with the results reported by Lane et al. (23), who discovered that caffeine's effect was long lasting among those people that took it on the everyday basis. Plus, caffeine increased HR, blood pressure and exaggerated perceived stress if consumed habitually. In addition, smoking has even higher impact on HRV, decreasing HRV considerably, since the coefficient was of high magnitude and it was resistible to all model specifications.

Moreover, the current study confirmed the results achieved by Gobel (24) that high strain took place during customer service tasks and just before leaving bus stops; the regulation stop variable has shown that drivers indeed are more stressed near the stops and usually the stop involves interaction with passengers.

Finally, the findings are in agreement with the job strain model presented by Karasek (10), where he has discovered that stress and work dissatisfaction takes place if the worker cannot meet the work demands, especially if he feels the ability and responsibility to change the situation. Therefore, when drivers have to align to strict time constraints they have increased stress level; and consequently they experience job strain, which is vividly underlined at regulation stops or during peak hour driving. It appears that even-headway holding strategy could diminish this time constraint requirement during bus driving, since if the forwarding bus is late then the upcoming bus is supposed to slow down and so forth; implying that drivers communicate according to the road situation and understand that being late induces a chain effect, which doesn't depend on the driver.

\section{CONCLUSIONS}

The current study analyzed the impact of alternative working conditions, individual attributes and emotional states on bus drivers' stress as measured through HRV. The results provide evidence that stress levels depend on the working conditions. In particular, stress levels diminished substantially when an even-headway strategy was 
Hlotova Y., Cats O. and Meijer S. (2014). Measuring Bus Driver's Occupational Stress under Changing Working Conditions. Transportation Research Record, 2415, 13-20. DOI: 10.3141/2415-02. Available at: http://rb.metapress.com/content/2707648k87262mh0/?genre=article\&id=doi\%3a10.3141\%2f2415-02

1 followed rather than a schedule-based control. These quantitative empirical findings confirm the trend reported by the driver union representatives following the field experiment which were contradicting to the a-priori expectations. The even-headway strategy allows greater flexibility to changing traffic conditions. It also implies a cooperative scheme that enables drivers to help each other, in particular when running behind schedule. Moreover, the analysis also provides evidence of elevated stress levels within the proximity of schedule adherence stops. Nevertheless more field studies on even-headway holding strategy are needed in order to provide robust guidelines for bus service providers.

Stress levels increased considerably under extreme weather conditions. However, the effect is attributed to a combination of uncertain and unusual traffic and work conditions. The last but not the least the study has shown that it is possible to set up experiments on stress of public transport operators in real working conditions, to collect reliable data with non-obtrusive, easy to use and affordable equipment which facilitates detailed data analysis.

The Garmin devices used for heart rate monitoring are a mainstream product developed for cyclists. The use of cheap GPS handheld computers with wireless heart rate monitor is rarely done in this type of studies, where the typical multi-electrode expensive and sensitive devices are the de-facto standard. The current study proved the good fit with other data, making the devices perfect options for practical studies and self-reporting of data. This reduces costs, the need for intrusive electrodes and the need for permanent expert availability.

The experiment design in this study was performed on a single bus line in Stockholm in order to control for potential intervening factors. Future studies might investigate the impact of route charactristics such as fare collection method, route length, demand levels and traffic congestion on occupational workload.

Future studies on occupational stress among bus drivers should investigate alternative solutions to mitigate stress in the domain of ergonomics, working conditions and situation awareness. In particular, the analysis of distinguished tasks accomplished by the bus driver would be instrumental in determining how specific patterns influence measured and reported stress levels. This could potentially contribute to the development of a more comfortable and attractive working environment by providing guidelines to bus operators on how to organize bus drivers' duty in order to reduce occupational stress.

\section{ACKNOWLEDGEMENTS}

The authors express their sincere gratitude to the bus service provider - Keolis Sverige - specifically to Robert Borger and Jonas Charanek from Stockholm City Operations - for their support throughout the experiment. The data collection was enabled by the driver union cooperation and the engagement of dedicated drivers for whom we are thankful.

\section{REFERENCES}

[1] Tse, L. M., Flin, R., Mearns K. Bus driver well-being review: 50 years of research. Transportation Research Part F: Traffic Psychology and Behaviour, Vol. 9, No 2, 2006, pp. 89-114. 
Hlotova Y., Cats O. and Meijer S. (2014). Measuring Bus Driver's Occupational Stress under Changing Working Conditions. Transportation Research Record, 2415, 13-20. DOI: 10.3141/2415-02. Available at: http://trb.metapress.com/content/2707648k87262mh0/?genre=article\&id=doi\%3a10.3141\%2f2415-02

1 Facilities Branch. Geneva, 1996.

2 [3] Long, L., Perry, J. L. Economic and Occupational Causes of Transit Operator 3 Absenteeism: A Review of Research. Transport Reviews: A Transnational 4 Transdisciplinary Journal, Vol. 5, No 3, 1985, pp. 247-267. among urban bus drivers in Copenhagen. Scandinavian Journal of Social Medicine, Vol. 9, No. 2, 1981, pp. 75-79.

[5] Wang, P. D., Lin, R. S. Coronary heart disease risk factors in urban bus drivers. Public Health, Vol. 115, No 4, 2001, pp. 261-264.

[6] Gustavsson, P., Alfredsson, L., Brunnberg, H., Hammar, N., Jakobsson, R., Reuterwall, C. Myocardial infarction among male bus, taxi, and lorry drivers in middle Sweden. Occupational and Environmental Medicine, Vol. 53, No 4, 1996, pp. 235-240.

[7] European Foundation for the Improvement of Living and Working Conditions. Work-related stress. 2007. http://www.eurofound.europa.eu/ewco/reports/TN0502TR01/TN0502TR01.pdf Accessed May 15, 2013

[8] Michie S. Causes and Management of stress at work. Occupational and Environmental Medicine, Vol. 59, 2002, pp. 67-72.

[9] Kompier M., Levi L. Stress at work: causes, effects and prevention. 1994. European Foundation for the Improvement of Living and Working Conditions. Loughlinstown House, Shankill, Co. Dublin, Ireland

[10] Karasek, R. A. Job demands, job decision latitude, and mental strain: Implications for job redesign. Administrative Science Quarterly, Vol. 24, No. 2, 1979, pp. 285-307.

[11] Evans GW, Carrère S. Traffic congestion, perceived control, and psychophysiological stress among urban bus drivers. Journal of Applied Psychology, Vol. 76, No. 5, 1991, pp. 658-63.

[12] Rigby K. Peak hour stress breaks motorists: 3D Survey, 2001. Available at: http://www.mynrma.com.au/about/media/peak-hour-stress-breaks-motorists-3dsurvey.htm Accessed May 2013.

[13] Gardell B., Aronsson, G., Barklof, K. The working environment for local public transport personnel. Stockholm, Sweden: The Swedish Work Environment Fund, 1983.

[14] Cats O., Larijani A.N., Ólafsdóttir A., Burghout W., Andreasson I. and Koutsopoulos H.N. Holding Control Strategies: A Simulation-Based Evaluation and Guidelines for Implementation. In Transportation Research Record: Journal of the Transportation Research Board, No. 2274, Transportation Research Board of the National Academies, Washington D.C., 2012, pp. 100-108.

[15] Cats, O. RETT 2 - Final report a field test for service regularity improvement. 2012. KTH - Royal Institute of Technology, Stockholm.

[16] Omboni, S., Isasti, G. How to measure interbeat interval in human patients. ResearchGate.

2013 http://www.researchgate.net/post/How_to_measure_the_interbeat_interval_in_human patients Accessed April, 12013

[17] Gamelin, X. F., Berthoin, S., Bosquet, L. Validity of the Polar S810 Heart Rate Monitor to Measure R-R Intervals at Rest. Medicine \& Science in Sports \& exercise: Official Journal of the American College of Sports Medicine, Vol. 38, No. 5, 2006, pp. 887-893.

[18] Kingsley, M., Lewis, M. J., Marson R. E. Comparison of Polar 810S and an 
Hlotova Y., Cats O. and Meijer S. (2014). Measuring Bus Driver's Occupational Stress under Changing Working Conditions. Transportation Research Record, 2415, 13-20. DOI: 10.3141/2415-02. Available at: http://trb.metapress.com/content/2707648k87262mh0/?genre=article\&id=doi\%3a10.3141\%2f2415-02

1 ambulatory ECG system for RR interval measurement during progressive exercise. 2 International Journal of Sports Medicine, Vol. 26, No 1, 2005, pp. 39-44.

3 [19] Porto, L. G. G., Junqueira, L.F. Comparison of time-domain short term heart 4 interval variability analysis using a wrist-worn heart rate monitor and the 5 conventional electrocardiogram. Pacing \& Clinical Electrophysiology, Vol. 32, No 1, 6 2009, pp. 43-52.

7 [20] Laukkanen, R. M. T., and Virtanen, P.K. Heart rate monitors: State of the art. 8 Journal of Sport Sciences, Vol. 16, No. 1, 1998, pp. 3-8.

9 [21] Hunter L.W. and Thatcher S.M.B. Feeling the heat: Effects of stress, 10 commitment and job experience on job performance. The Academy of Management 11 Journal, Vol. 40, No. 4, 2007, pp. 953-968.

12 [22] Aldwin, C.M., Sutton K.J., Chiara G., Spiro A. Age differences in stress, coping, 13 and appraisal: Findings from the Normative Aging Study. Journal of Gerontology: 14 Psychological Sciences, Vol. 51 No. 4, 1996, pp. 179-88.

15 [23] Lane, J.D. , Pieper, C.F., Phillips-Bute, B., Bryant J.E., Kuhn, C.M. Caffeine 16 Affects Cardiovascular and Neuroendocrine Activation at Work and Home. 17 Psychosomatic Medicine. Vol. 64, 2002, pp. 595-603.

18 [24] Gobel, M., Springer, J., Scheriff, J. Stress and strain of short haul bus drivers: 19 Psychophysiology as a design oriented method for analysis. Ergonomics, Vol. 41 20 No.5, 1998, pp. 563-80. 